Open Access

\title{
Objective and subjective measures of neighborhood environment (NE): relationships with transportation physical activity among older persons
}

Ma Shwe Zin Nyunt ${ }^{1}$, Faysal Kabir Shuvo ${ }^{2}$, Jia Yen Eng ${ }^{3}$, Keng Bee Yap ${ }^{4}$, Samuel Scherer ${ }^{5,6}$, Li Min Hee ${ }^{9}$, Siew Pang Chan ${ }^{7,8}$ and Tze Pin $\mathrm{Ng}^{1,10^{*}}$

\begin{abstract}
Background: This study examined the associations of subjective and objective measures of the neighbourhood environment with the transportation physical activity of community-dwelling older persons in Singapore.

Method: A modified version of the Neighborhood Environment Walkability Scale (NEWS) and Geographical Information System (GIS) measures of the built environment characteristics were related to the frequency of walking for transportation purpose in a study sample of older persons living in high-density apartment blocks within a public housing estate in Singapore. Relevant measured variables to assess the complex relationships among built environment measures and transportation physical activity were examined using structural equation modelling and multiple regression analyses.

Results: The subjective measures of residential density, street connectivity, land use mix diversity and aesthetic environment and the objective GIS measure of Accessibility Index have positively significant independent associations with transportation physical activity, after adjusting for demographics, socio-economic and health status.
\end{abstract}

Conclusion: Subjective and objective measures are non-overlapping measures complementing each other in providing information on built environment characteristics. For elderly living in a high-density urban neighborhood, well connected street, diversity of land use mix, close proximity to amenities and facilities, and aesthetic environment were associated with higher frequency of walking for transportation purposes.

Keywords: Built environment, Transportation physical activity, Elderly, Neighborhood environment walkability scale (NEWS), Geographical information system (GIS), Structural equation model (SEM)

\section{Introduction}

Successful "aging in place" involves enabling the elderly to be physically active and independent in performing instrumental activities of daily living for meaningful social engagement within their own community and neighborhood. The physical characteristics of the neighborhood built environment play an important intervening

\footnotetext{
* Correspondence: pcmngtp@nus.edu.sg

${ }^{1}$ Gerontology Research Programme, Department of Psychological Medicine, Yong Loo Lin School of Medicine, National University of Singapore, Kent Ridge, Singapore

${ }^{10}$ Yong Loo Lin School of Medicine, Department of Psychological Medicine, National University Hospital, National University of Singapore, 5 Lower Road, Kent Ridge 119074, Singapore

Full list of author information is available at the end of the article
}

role in supporting or limiting physical activity and functional independence of elderly people living in their community $[1,2]$.

Recent research examining the links between characteristics of the physical neighborhood environment (NE) and the frequency and duration of transport-related physical activity (PA) (e.g., walking to the grocery store) within urban communities have variously used perceived measures obtained by interviews and geospatial data based on geographical information system (GIS) analyses of archival maps (for a review of studies, see study by Lin, et al., 2010) [3]. The development and evaluation of measures of the built environment are still at a relatively early stage. There remains much to be explored, especially from a 
public health point of view, about the relevance and utility of various elements of the built environment to different domains of physical activity (transportation and leisure) and other functional outcomes for various population groups including the elderly [3].

The extent to which objective and subjective measures of the neighbourhood environment overlap or complement each other in influencing the level of physical activity and functional independence is not well elucidated. Prior studies $[4,5]$ indicate a poor level of agreement between objective and perceived measures of the built environment. Both objective and perceived measures evaluated in the same model showed independent associations with physical activity, thus suggesting that the same aspects of the built environment should be ascertained with both objective and subjective measures. Few studies have explored the individual, combined and relative contributions of subjectively or objectively measured attributes of the built environment to physical activity by the elderly.

Studies show that GIS measures of the amount of automobile traffic and number of commercial establishments in the neighborhood were reportedly associated with increased levels of overall walking activity [6]; and GIS measures of land-use diversity was reportedly associated with greater independence in instrumental activities of daily living [1]. In Japan, perceived measures of good bicycle lanes, non-ownership of household motor vehicles and access to exercise facilities were found to be significantly associated with higher levels of transportation physical activity among seniors, whereas access to public transportation was not [7]. This suggests that the relevance of a wide range of built environment characteristics to transportation physical activity and functional independence may differ among countries, according to the level and socio-cultural characteristics of their infrastructural development.

Singapore is characterized by its small land size (718.3 $\mathrm{km}^{2}$ in 2014 ) and high density population density (7615 persons $/ \mathrm{km}^{2}$ in 2014), with $82 \%$ of the population residing in high rise apartments [8]. With its exceptionally rapid rate of population ageing, approximately $30 \%$ of the total residential population of Singapore will be above 65 years of age in 2050, up from $10 \%$ in 2010 . The authorities have in recent years begun to pay more attention to developing an urban infrastructure that provides an elder-friendly living environment in support of active aging.

The aim of this study was to assess the use of both perceived assessments and objective GIS measures of the neighborhood environment to examine their independent and combined associations with transportation physical activity among community dwelling elderly in Singapore.

\section{Methods}

\section{Study population}

A total of 402 older persons ( $\geq 55$ years of age) who were resident for at least 5 years in a neighborhood located in three public housing precincts in the South Central region of Singapore participated in this study. They were among 2802 participants in an ongoing population-based longitudinal ageing cohort study (Singapore Longitudinal Aging Study Wave 2) conducted in 2011 and 2012. We invited one elderly resident per residential address to participate in the study. Older persons with severe physical disability and communication difficulties were excluded. Trained research nurses visited their homes to conduct face-to-face interviews. The study was approved by the National University of Singapore Institutional Review Board (NUSIRB), and all study participants gave informed consent.

\section{Measurements}

The subjective measure of the perceived neighborhood environment used an adapted version of the Neighborhood Environment Walkability Scale (NEWS) [9]. It comprises 67 items which are grouped into 8 factors:

a Residential density - types of residences in the neighborhood

b Land use mix - diversity ("Stores, facilities, and other things in your neighbourhood")

was assessed by reports of facilities and amenities in the neighborhood, such as "About how long would it take to get from your home to the nearest businesses or facilities listed below if you walked to them?" and "How much it influences your participation in doing activities"

c Street connectivity-includes streets in the neighborhood, places for walking and cycling and neighborhood surroundings

d Land use mix - access (Access to services) such as "I can do most of my shopping at local stores", "It is easy to walk to a transit stop (bus, train) from my home" ( 1 = strongly disagree, 2 = somewhat disagree, 3 = somewhat agree, $4=$ strongly agree)

e Infrastructure-places for walking and cycling

f Aesthetics (Neighborhood surroundings)

g Traffic safety

h Safety from crime $[10,11]$.

Objective measures of the neighborhood environment was based on Geographical Information System (GIS) variables measured in Euclidean or straight-line distances buffer within $500 \mathrm{~m}$ of the centroid of a neighborhood using the software ArcGIS ${ }^{\oplus}$ version 10 [12]: 
a Street connectivity-based on the number of true intersections within a given area, was defined by the number of street links divided by the number of street nodes within the buffer area.

b Residential density - the number of dwelling units was divided by the land area in residential use within the area

c Land use mix - the distribution of development across five uses (residential, commercial, industrial, recreation and other) is assessed to measure the land use mix.

d Public park density-obtained by dividing the total area of public parks by the total area of the buffer and multiplying by 100

The Walkability Index was in turn derived as a composite value of combinations and weights of individual built environment characteristics, including residential density, street connectivity, land-use mix [13-16]. Since urban Singapore is characterized by a mixed land-used and compact urban environment, the net retail area was omitted in this study. Because of the unavailability of GIS layer of walkable paths within the study area, the impact of street networks is considered to be homogenous. "Residential lot coverage" and "street density" were used as proxy variables respectively for residential density and street connectivity. Therefore, the modified walkability index included residential lot coverage, street density and land-use mix. The built environment characteristics were measured in numerical values by $\mathrm{ArcGIS}^{\circ}$ and Z-scores were calculated after arbitrarily dividing the whole study area into 18 zones (study area units). The constituent variables of walkability index, i.e. residential density, street density and land-use mix, were calculated based on the formulas provided in the Neighborhood Environment for Active Transport-Geographic Information Systems(NEAT-GIS) protocol [17]. Specifically,

Walkability index $=$ Residential lot coverage $+1.5 \times$ street density + land use mix

The Accessibility Index was assessed by measuring the walking access to 30 types of community service and amenity destinations to which proximity could plausibly encourage residents to walk more for leisure or transport [18]. Accessibility index is calculated for the 18 individual zones based on the multiplication of the sum of building weight within each zone and the residential density:

Accessibility index $=$ building weights of the zone $x$ residential density.

Both the Walkability and Accessibility Indexes were categorized into 3 levels, namely low, medium and high.

Physical activity (walking for transportation purpose); The study participants were also asked "How often do you walk from your house to (nearest) various types of businesses or facilities" with response ranging from never to daily. The scores of all items were summed and a higher scores denoting more frequently walking for transport. Transportation physical activity was the primary outcome of the analysis.

Covariates The study participant's self-rated health was reported as 'excellent', 'very good', 'good', 'poor', or 'very poor'. Physical Performance: gait and balance were measured with the performance oriented mobility assessment (POMA) tool [19]. Static sitting balance (rising from the sitting position without using hands) was assessed using graded scores by the need for assistance and the number of attempts; standing balance was assessed within the first $5 \mathrm{~s}$ after the subject's sternum was gently pushed by the examiner, and when stance was stabilized. Staggering or excessive sway of the subject was examined with the subject standing and eyes closed. Steadiness and continuity of steps were

Table 1 Sample characteristics $(n=402)$

\begin{tabular}{|c|c|c|c|}
\hline Variables & & Number & Percent \\
\hline \multirow[t]{2}{*}{ Gender } & Male & 157 & 39.1 \\
\hline & Female & 244 & 60.7 \\
\hline \multirow[t]{3}{*}{ Age } & Mean (SD) & 69.13 & $(8.53)$ \\
\hline & $>=65$ & 265 & 65.9 \\
\hline & $<65$ & 137 & 34.1 \\
\hline \multirow[t]{2}{*}{ Ethnicity } & Non-Chinese & 68 & 16.9 \\
\hline & Chinese & 334 & 83.1 \\
\hline \multirow[t]{2}{*}{ Education } & No formal/Primary & 287 & 71.4 \\
\hline & Secondary \& Above & 113 & 28.1 \\
\hline \multirow[t]{3}{*}{ Housing status } & 1 or 2 Rooms & 169 & 42.0 \\
\hline & 3 rooms & 143 & 35.6 \\
\hline & 4 or 5 Rooms & 90 & 22.4 \\
\hline \multirow[t]{5}{*}{ Self-rated health status } & Poor & 4 & 1.0 \\
\hline & fair & 112 & 27.9 \\
\hline & Good & 212 & 52.7 \\
\hline & Very good & 62 & 15.4 \\
\hline & Excellent & 12 & 3.0 \\
\hline POMA Balance score & Mean (SD) & 15.67 & $(1.33)$ \\
\hline POMA Gait score & Mean (SD) & 11.70 & $(0.94)$ \\
\hline \multicolumn{4}{|c|}{ GIS Built environment measures } \\
\hline \multirow[t]{3}{*}{ Walkability index } & Low & 48 & 11.9 \\
\hline & Medium & 255 & 63.4 \\
\hline & High & 96 & 24.4 \\
\hline \multirow[t]{3}{*}{ Accessibility index } & Low & 137 & 34.1 \\
\hline & Medium & 165 & 41.0 \\
\hline & High & 99 & 24.6 \\
\hline \multicolumn{4}{|l|}{ Physical activity } \\
\hline Walking for transportation & Mean (SD) & 25.16 & $(0.58)$ \\
\hline
\end{tabular}


observed with the subject turning in a complete $360^{\circ}$ circle. The gait assessment was performed with the subject walking $6 \mathrm{~m}$ and returning quickly to the starting point, noting the ability to initiate walking and any hesitancy, step height and length, the lack of symmetry or inability to clear the floor, step continuity, deviation in the path and walking stance. The POMA scores for balance and gait were tallied separately using standard scoring criteria. Socio-demographic data included age, gender, ethnicity, educational attainment and housing type.

\section{Data analysis}

Structural Equation Models (SEM) based on robust maximum-likelihood estimation were used to perform regression analysis with observed (measured or manifest) data and factor analysis with latent variables simultaneously, given the complex relationships among the considered variables. Subjective and objective neighborhood environment (NE) measurement constructs and socio-economic and physical health status were treated as latent variables, as they were not directly measured but inferred from the observed variables. Raw scores of all measured variables in every factor of objective and subjective NE measures were used in analysis. The subjective and objective NE measures were linked with a covariance given their similar nature in explaining the level of transportation physical activities. In Confirmatoty Factor Analysis, a measurement model was built for each subjective and objective measure factors. The first indicator of each latent variable was fixed at 1.0, in order to create a metric scale. Indicators which were not significantly correlated to the latent variables were removed from the model.

Multiple Regression Models were used to examine the association of subjective and objective measures of the built environment characteristics (independent variables) with transportation physical activity (dependent variables). In stepwise models, socio-economic variables, self-rated health status, and POMA balance and gait scores were analyzed in the base model. Next, we added subjective or GIS measures of the built environment in separate models (1a and $1 \mathrm{~b}$ ). Finally, we added both subjective and objective measures together to the base model (Model 2). Adjusted R squared changes from base model to full model (Model 2) were identified.

Data analysis was carried out with Stata MP version 13.0 [20]. The root mean square errors of approximation (RMSEA) were generated as the default index of model fit $[21,22]$. All statistical tests were performed at $5 \%$ level of significance.

\section{Results}

The sample characteristics are depicted in Table 1. The mean age of the study participants was 69.1 years. They were dominantly female (60.7\%), and of Chinese ethnicity $(83.1 \%)$. About $71.4 \%$ had primary or no formal education, and approximately $42 \%$ lived in 1 or 2 room public housing apartments. The majority of the subjects rated their health as good, very good or excellent (81.1\%).

The confirmatory factor analyses showed that most of the manifest variables loaded satisfactorily on their respective latent variables, representing transportation physical activity and eight subjective $\mathrm{BE}$ measures, namely residential

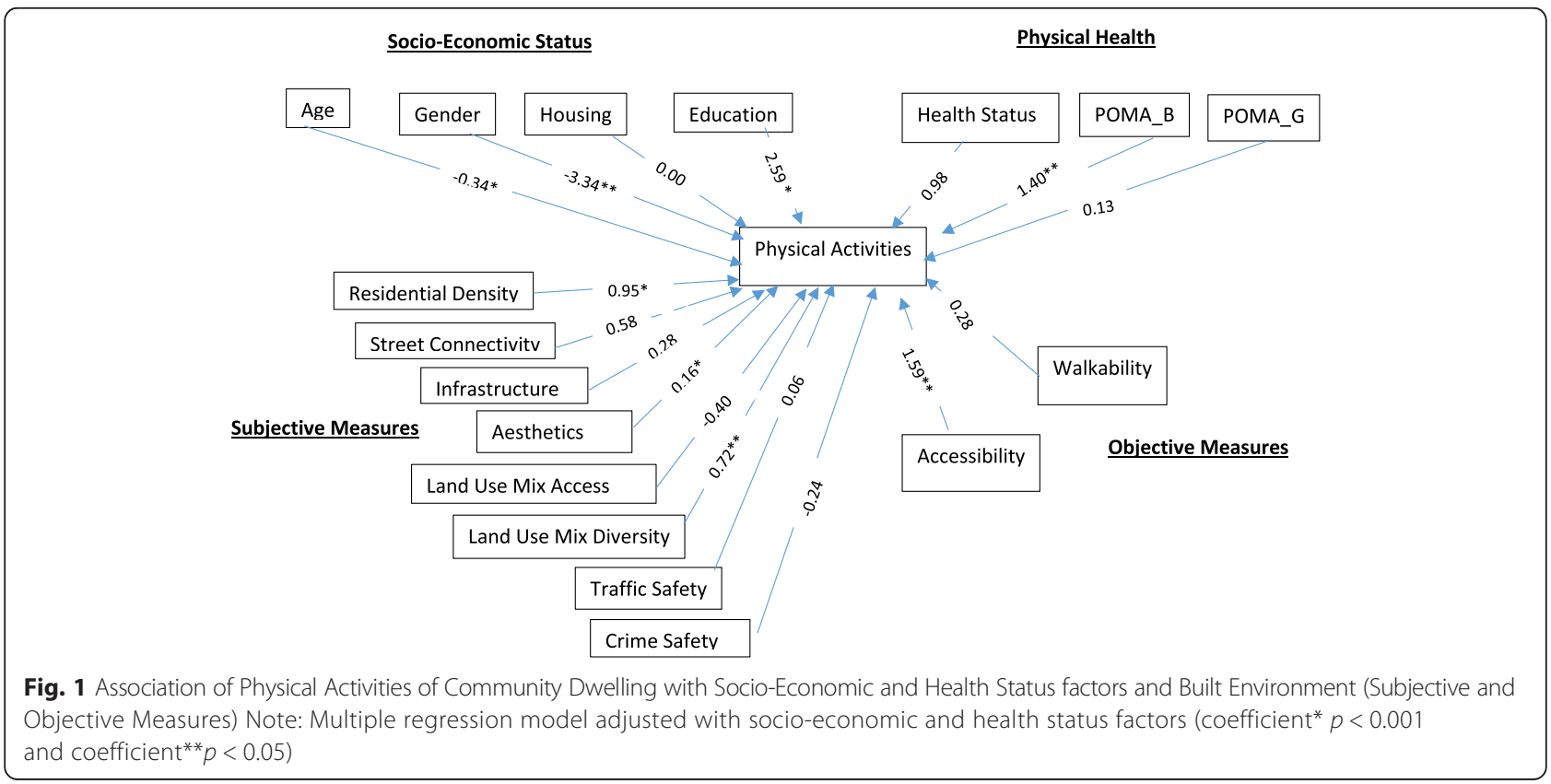


density, well connected streets in the neighborhood (street connectivity), land use mix access, infrastructure walk cycle, aesthetics, traffic safety, crime safety and land use density. Details of the CFA are described in the Appendix, and results of factor analysis are shown in Tables 3,4 , and 5.

In multiple regression analyses, we ascertained whether the eight subjective NE measures and two objective GIS indices (walkability and accessibility) were significantly associated with transportation physical activity (See Fig. 1). Covariates in the regression analyses included socioeconomic variables (age, gender, housing type and educational attainment), and physical health (health status, POMA Balance Score and POMA Gait Score). To facilitate comparison, four models were built. These included the base model (with socio-economic variables only), base model and subjective measures of built environment (Model 1a), base model and objective measures (Model 1b) and finally the full model (Model 2) comprised all the base model, subjective and objective variables (Table 2).

The base model (adjusted R-squared 0.19) showed that older $(\beta=-0.34, p<0.001)$, female subjects $(\beta=-3.34$, $p<0.05)$ were more likely to have a lower level of transportation physical activity and elderly with higher education $(\beta=2.59, p<0.001)$ and better physical performances $(\beta=1.40, p<0.05)$ were more likely to have

Table 2 Association of physical activities of community dwelling with built environment (Subjective and Objective Measures) after adjusted with socio-economic and health status (Multiple regression Model)

\begin{tabular}{|c|c|c|c|c|c|}
\hline & Coefficient & $95 \% \mathrm{Cl}$ & & $p$-value & Adjusted R2 \\
\hline Base model variables: & & & & & 0.19 \\
\hline Age & -0.34 & -0.49 & -0.19 & $<0.001$ & \\
\hline Gender & -3.34 & -5.76 & -0.91 & 0.007 & \\
\hline Housing type & 0.00 & -0.01 & 0.01 & 0.56 & \\
\hline Education & 2.59 & 1.18 & 4.01 & $<0.001$ & \\
\hline Self- rated health status & 0.98 & -0.57 & 2.53 & 0.21 & \\
\hline POMA Balance score & 1.40 & 0.40 & 2.39 & 0.006 & \\
\hline POMA gait score & 0.13 & -1.27 & 1.54 & 0.85 & \\
\hline Model 1a: Base model + subjective measures & & & & & 0.43 \\
\hline Resident density & 1.07 & 0.58 & 1.57 & $<0.001$ & \\
\hline Street connectivity & 0.69 & 0.05 & 1.34 & 0.04 & \\
\hline Land use mix-access & -0.42 & -0.93 & 0.10 & 0.11 & \\
\hline Land use mix-diversity & 0.72 & 0.18 & 1.25 & 0.01 & \\
\hline Infra-structure for walking and cycling & 0.22 & -0.23 & 0.67 & 0.34 & \\
\hline Aesthetics & 0.17 & 0.12 & 0.21 & $<0.001$ & \\
\hline Traffic safety & 0.02 & -0.31 & 0.35 & 0.90 & \\
\hline Crime safety & -0.23 & -0.66 & 0.21 & 0.31 & \\
\hline Model 1b: Base model + objective measures & & & & & 0.24 \\
\hline GIS Walkability & 1.05 & -1.06 & 3.15 & 0.33 & \\
\hline GIS Accessibility & 4.28 & 2.61 & 5.94 & $<0.001$ & \\
\hline Model 2: Base model + subjective + objective measures & & & & & 0.43 \\
\hline Resident density & 0.95 & 0.44 & 1.46 & $<0.001$ & \\
\hline Street connectivity & 0.58 & -0.07 & 1.24 & 0.08 & \\
\hline Land use mix-access & -0.40 & -0.92 & 0.13 & 0.14 & \\
\hline Land use mix-diversity & 0.72 & 0.18 & 1.26 & 0.009 & \\
\hline Infra-structure for walking and cycling & 0.28 & -0.17 & 0.73 & 0.22 & \\
\hline Aesthetics & 0.16 & 0.11 & 0.21 & $<0.001$ & \\
\hline Traffic safety & 0.06 & -0.27 & 0.39 & 0.72 & \\
\hline Crime safety & -0.24 & -0.68 & 0.20 & 0.29 & \\
\hline GIS Walkability & 0.28 & -1.61 & 2.17 & 0.77 & \\
\hline GIS Accessibility & 1.59 & 0.02 & 3.15 & 0.05 & \\
\hline
\end{tabular}


a higher level of transportation physical activity. Model 1a (adjusted R-squared 0.43) showed R-squared change of 0.24 , suggesting that subjective $B E$ measures gave a substantially larger contribution to the level of transportation physical activity than objective measures, which was associated with a R-squared change of 0.05 in Model 1b (Rsquared $=0.24$ ). The final full model (Model 2) indicated that combining subjective and objective measures did not substantially increase the total R-squared. Among the eight subjective measures, resident density $(\beta=0.95, p<0.001)$, land-use mix density $(\beta=0.72, p<0.05)$ and aesthetic environment $(\beta=0.17, p<0.001)$ were significant in explaining the level of transportation physical activity. Of the objective GIS measure, only the Accessibility Index ( $\beta=$ $1.59, p<0.05)$ was significant.

\section{Discussion}

We found in this study of older persons living in a highdensity urban neighborhood in Singapore that residential density, diversity of land use mix, close proximity to amenities and facilities, and aesthetics were demonstrably associated with higher frequency of walking for transportation purposes, such as going to and from shopping. Our findings are consistent with other reports that residents are more likely to engage in transportation-related physical activity if they live in neighbourhoods with higher-

Table 3 Factor analysis of transportation physical activity

\begin{tabular}{|c|c|c|c|c|}
\hline Measurements & Coefficient & $95 \%$ C.I & & $P$ value \\
\hline Provision shop & 1 (Constrained) & & & \\
\hline Wet market & 1.24 & 0.74 & 1.75 & $<0.001$ \\
\hline Supermarket & 1.67 & 1.05 & 2.30 & $<0.001$ \\
\hline Hardware store & 0.58 & 0.34 & 0.82 & $<0.001$ \\
\hline Laundry/dry cleaners & 0.13 & 0.05 & 0.21 & 0.002 \\
\hline Clothing shops & 0.39 & 0.18 & 0.59 & $<0.001$ \\
\hline Hairdresser/barber shop & 0.52 & 0.24 & 0.79 & $<0.001$ \\
\hline Hawker center & 1.76 & 1.10 & 2.43 & $<0.001$ \\
\hline Coffee shop & 1.73 & 1.06 & 2.39 & $<0.001$ \\
\hline Fast food restaurant & 0.70 & 0.40 & 1.01 & $<0.001$ \\
\hline Non-fast food restaurant & 0.89 & 0.54 & 1.24 & $<0.001$ \\
\hline $\begin{array}{l}\text { Bank/Automated Teller } \\
\text { Machines (ATM) }\end{array}$ & 1.40 & 0.88 & 1.92 & $<0.001$ \\
\hline Post office & 0.83 & 0.50 & 1.16 & $<0.001$ \\
\hline Library & 1.00 & 0.62 & 1.39 & $<0.001$ \\
\hline Religious institutions & 0.88 & 0.50 & 1.26 & $<0.001$ \\
\hline Elementary school & 0.80 & 0.46 & 1.13 & $<0.001$ \\
\hline Other schools & 0.24 & 0.10 & 0.38 & $<0.001$ \\
\hline Book store & 0.27 & 0.13 & 0.40 & $<0.001$ \\
\hline Video store & 0.12 & 0.04 & 0.20 & $<0.001$ \\
\hline Movie theatre & 0.18 & 0.09 & 0.26 & $<0.001$ \\
\hline Medicinal shops & 0.14 & -0.09 & 0.37 & 0.239 \\
\hline Clinics/dentals & 0.39 & 0.20 & 0.58 & $<0.001$ \\
\hline Nearest bus stop & 1.42 & 0.87 & 1.97 & $<0.001$ \\
\hline $\begin{array}{l}\text { Nearest Mass Rapid } \\
\text { Transport (MRT) station }\end{array}$ & 1.58 & 1.00 & 2.16 & $<0.001$ \\
\hline Recreational park & 0.73 & 0.31 & 1.16 & $<0.001$ \\
\hline Community club/Residents' Committee & 0.76 & 0.38 & 1.14 & $<0.001$ \\
\hline Swimming pools & 0.36 & 0.18 & 0.55 & $<0.001$ \\
\hline Gym or fitness facility & 0.64 & 0.28 & 1.00 & $<0.001$ \\
\hline Singapore pools & 0.25 & 0.05 & 0.45 & 0.016 \\
\hline Senior activity center/club & -0.32 & -0.73 & 0.08 & 0.116 \\
\hline
\end{tabular}


density housing, easier access to a range of destinations, well connected street networks with aesthetic environment and a mix of land-use zones [23, 24].

Our study further provides insights on the use of subjective and objective measures of neighbourhood environment characteristics in relation to transportation physical activity among older adults. Both subjective and objective measures of accessibility reflecting proximity to community services and amenity destinations that could plausibly encourage residents to walk more for leisure or transport [18] were used in this study. Interestingly, GIS measure of accessibility was demonstrated to be significantly associated with transportation physical activity, whereas perceived measure of accessibility was not. This suggests that the objective measure was a more valid measure of accessibility than the subjective measure. Conversely, the GIS measure of walkability (constituted by residential density, street connectivity and land-use mix) was not significantly associated with transportation physical activity, whereas subjective measures of perceived street connectivity, land use mix-diversity and aesthetic environment were significantly associated. They thus appear to provide additional information predicting the probability of more frequent transportation physical activity that were not measured by the objective measure. In agreement with prior studies $[3,4]$, there were no uniformly strong correlations between objective and perceived measures for different built environment attributes, suggesting that the same aspect of the built environment may be measured by one measure that is not fully measured by

Table 4 Factor analysis of subjective measures of built environment

\begin{tabular}{|c|c|c|c|c|}
\hline \multirow{2}{*}{$\begin{array}{l}\text { Measurements } \\
\text { Residential density (Factor 1) }\end{array}$} & \multirow[t]{2}{*}{ Coefficient } & \multicolumn{2}{|l|}{$95 \% \mathrm{Cl}$} & \multirow[t]{2}{*}{$p$} \\
\hline & & & & \\
\hline Bungalow & 1 (constrained) & & & \\
\hline Shophouses/house (1-3 stories) & 1.33 & 1.27 & 1.39 & $<0.001$ \\
\hline Apartment/condominium (1-3 stories) & 5.94 & 1.53 & 10.36 & 0.008 \\
\hline Apartment/condominium (4-6 stories) & 5.86 & 1.44 & 10.27 & 0.009 \\
\hline Apartment/condominium (7-12 stories) & 43.89 & 13.11 & 74.68 & 0.005 \\
\hline Apartment/condominium (more than 13 stories) & 45.51 & 13.88 & 77.14 & 0.005 \\
\hline \multicolumn{5}{|l|}{ Street Connectivity (Factor 2) } \\
\hline Connecting and covered walkways & 1 (constrained) & & & \\
\hline Sufficient time for pedestrian crossing & 1.20 & 0.94 & 1.46 & $<0.001$ \\
\hline Nearest traffic light & 0.93 & 0.75 & 1.10 & $<0.001$ \\
\hline \multicolumn{5}{|l|}{ Land Use Mix Access (Factor 3) } \\
\hline Store within easy walking distance & 1 (constrained) & & & \\
\hline Places within easy walking distance & 0.66 & 0.56 & 0.75 & $<0.001$ \\
\hline Easy to walk to bus \& Mass Rapid Transport stations & 0.99 & 0.99 & 1.00 & $<0.001$ \\
\hline Many steps/stairs difficult to walk & 0.66 & 0.56 & 0.75 & $<0.001$ \\
\hline \multicolumn{5}{|l|}{ Infrastructure Walk cycle (Factor 4) } \\
\hline Sidewalks on most streets & 1 (constrained) & & & \\
\hline Well-designed sidewalks & 1.37 & 1.13 & 1.61 & $<0.001$ \\
\hline Bicycles lanes & -2.02 & -2.48 & -1.55 & $<0.001$ \\
\hline Sidewalks separated from streets by barriers & 2.08 & 1.68 & 2.47 & $<0.001$ \\
\hline Cars parked between sidewalks and main streets & 0.46 & 0.17 & 0.75 & 0.002 \\
\hline Grass separaters separates roads from sidewalks & 2.02 & 1.63 & 2.41 & $<0.001$ \\
\hline \multicolumn{5}{|l|}{ Aesthetics (Factor 5) } \\
\hline Shade for sidewalks & 1 (constrained) & & & \\
\hline Trees along the streets & 1.12 & 0.58 & 1.67 & $<0.001$ \\
\hline Interesting things to look while walking & 0.02 & -0.17 & 0.22 & 0.81 \\
\hline Free from litter & -0.23 & -0.43 & -0.03 & 0.02 \\
\hline Trees and garden landscaping & 0.22 & -0.01 & 0.46 & 0.06 \\
\hline Attractive buildings/homes & -0.21 & -0.37 & -0.05 & 0.01 \\
\hline
\end{tabular}


Table 5 Factor analysis of Subjective measures (Continued)

\begin{tabular}{|c|c|c|c|c|}
\hline \multirow{2}{*}{$\frac{\text { Measurements }}{\text { Traffic safety (Factor 6) }}$} & \multirow[t]{2}{*}{ Coefficient } & \multicolumn{2}{|l|}{$95 \% \mathrm{Cl}$} & \multirow[t]{2}{*}{$\mathrm{p}$ value } \\
\hline & & & & \\
\hline Much traffic along the streets & 1 (constrained) & & & \\
\hline Much traffic along nearby streets & 1.00 & 0.75 & 1.25 & $<0.001$ \\
\hline Traffic speed slow & 0.94 & 0.69 & 1.19 & $<0.001$ \\
\hline Traffic speed slow on most nearby streets & 1.00 & 0.75 & 1.26 & $<0.001$ \\
\hline Drivers exceed the posted speed limits & 1.02 & 0.76 & 1.28 & $<0.001$ \\
\hline Drivers stopped at pedestrians crossing & 1.51 & 1.20 & 1.82 & $<0.001$ \\
\hline Pedestrians crossings and signals & 1.40 & 1.11 & 1.69 & $<0.001$ \\
\hline Pedestrians crossings help walkers feel safe crossing & 1.69 & 1.36 & 2.03 & $<0.001$ \\
\hline Overhead bridges to cross the road safely & 1.76 & 1.38 & 2.14 & $<0.001$ \\
\hline \multicolumn{5}{|l|}{ Crime safety (Factor 7) } \\
\hline Neighbourhood streets well lit at night & 1 (constrained) & & & \\
\hline Walkers and bikers on the streets & 0.80 & 0.61 & 0.99 & $<0.001$ \\
\hline See and speak to other people when walking & 1.11 & 0.90 & 1.33 & $<0.001$ \\
\hline High crime rate & -1.39 & -1.63 & -1.15 & $<0.001$ \\
\hline Crime rate unsafe to go on walks during the day & -1.69 & -1.94 & -1.45 & $<0.001$ \\
\hline Crime rate unsafe to go on walks during at night & -1.84 & -2.11 & -1.57 & $<0.001$ \\
\hline \multicolumn{5}{|l|}{ Land use diversity (Factor 8) } \\
\hline Provisions shop & 1 (constrained) & & & \\
\hline Wet market & 1.06 & 0.83 & 1.29 & $<0.001$ \\
\hline Supermarket & 1.51 & 1.16 & 1.87 & $<0.001$ \\
\hline Hardware store & 1.95 & 1.52 & 2.37 & $<0.001$ \\
\hline Laundry/dry cleaner & 0.21 & 1.52 & 2.34 & $<0.001$ \\
\hline Clothing & 1.89 & 1.52 & 2.26 & $<0.001$ \\
\hline Hairdresser & 1.53 & 1.25 & 1.82 & $<0.001$ \\
\hline Hawker center & 1.18 & 0.94 & 1.41 & $<0.001$ \\
\hline Coffee shop & 1.18 & 0.96 & 1.41 & $<0.001$ \\
\hline Fast food restaurant & 1.27 & 0.91 & 1.64 & $<0.001$ \\
\hline Non-fast food restaurant & 1.36 & 0.98 & 1.75 & $<0.001$ \\
\hline Bank/Automated Teller Machines (ATM) & 1.84 & 1.49 & 2.20 & $<0.001$ \\
\hline Post office & 1.70 & 1.31 & 2.09 & $<0.001$ \\
\hline Library & 1.19 & 0.89 & 1.50 & $<0.001$ \\
\hline Religious institutions & 0.96 & 0.61 & 1.30 & $<0.001$ \\
\hline Elementary school & 1.66 & 1.26 & 2.06 & $<0.001$ \\
\hline Other schools & 1.68 & 1.29 & 2.07 & $<0.001$ \\
\hline Video store & 1.66 & 1.27 & 2.04 & $<0.001$ \\
\hline Movie theatre & 1.04 & 0.77 & 1.31 & $<0.001$ \\
\hline Medicinal shops & 1.61 & 1.31 & 1.92 & $<0.001$ \\
\hline Clinics/dentals & 1.76 & 1.41 & 2.11 & $<0.001$ \\
\hline Nearest bus stop & 0.76 & 0.60 & 0.93 & $<0.001$ \\
\hline Nearest mass rapid transport (MRT) stations & 0.85 & 0.53 & 1.17 & $<0.001$ \\
\hline
\end{tabular}


Table 5 Factor analysis of Subjective measures (Continued) (Continued)

\begin{tabular}{|c|c|c|c|c|}
\hline Recreational park & 1.74 & 1.33 & 2.14 & $<0.001$ \\
\hline Community club/residents' committee & 1.88 & 1.49 & 2.27 & $<0.001$ \\
\hline Swimming pools & 1.79 & 1.42 & 2.17 & $<0.001$ \\
\hline Gym or fitness facility & 1.48 & 1.08 & 1.87 & $<0.001$ \\
\hline Singapore pools & 2.14 & 1.74 & 2.53 & $<0.001$ \\
\hline Senior activity center/club & 1.22 & 0.90 & 1.53 & $<0.001$ \\
\hline Book store & 1.06 & 0.75 & 1.37 & $<0.001$ \\
\hline
\end{tabular}

the other. Our study suggests that subjective and objective measures complement each other in providing information on built environment characteristics.

In this study, we also confirmed the manifest variables which were relevant for the measuring built environment attributes of high-density urban neighborhoods typical for over $80 \%$ of the population in Singapore. Uniquely, these public housing estates have wet markets and supermarket for grocery, and almost all elderly do not own cars. Therefore, dead end streets, shopping at local stores and difficulty parking were not relevant measurement items in the Singapore context. This suggests that the measurement and modification of built environment characteristics for improved transportation physical activity and mobility are unique to a location, and need to be relevant to the level and socio-cultural context.

A strength of this study is the use of both subjective and objective measures of built environment for small geographic units. The results in this study is generalizable to many neighborhoods in Singapore, since the study population and geographical site is typical of many older public housing estates. However, further studies are required to determine the variations in the influence of the neighborhood environment on older persons' mobility by different housing and environmental design types.

There are limitations in this study. Because of its cross sectional design, the causality of the observed associations should be cautiously interpreted. The accuracy of questionnaire responses by elderly people may be subject to recall bias and inaccuracy, and the self-reported data on subjective measures of the neighborhood environment and physical activity may contribute to a positive response bias favoring a closer association of two selfreported measures. Instead, actigraphy may provide a more objective measure of physical activity.

In conclusion, the important role of the physical built environment in influencing the level of transportation physical activity of older persons living in the community is firmly supported in this study. Our study provides supporting evidence to suggest that urban housing and environmental design planning that provide adequate number of facilities and amenities in close proximity to apartment blocks, and aesthetic neighborhood environment will positively influence older residents to walk more for transport, promote independent living in the community and maintain their quality of life.

\section{Appendix}

Transportation physical Activity The manifest variables considered were carefully selected so that they were relevant to Singapore's context, in terms of socio-demographic characteristics, culture and environmental features. A number of items in the original questionnaires and instruments were omitted before analysis. These included "shopping at local stores", "dead end street in the neighborhood", "car parking difficulty in shopping areas", "interesting things to look in the neighborhood" and "exhaust fumes". In Singapore, almost every public housing estate has wet markets and supermarkets for grocery and most of the elderly are not car owners. Therefore, dead end streets, shopping at local stores and difficulty parking are not relevant in this study. In addition, elderly residents usually do not find their neighbourhood interesting or exciting because they have been living there for many years and all housing estates are equipped with similar basic infrastructures and facilities, owing to the government's urban planning.

Based on the SEM framework, the confirmatory factor analyses showed that most of the manifest variables loaded satisfactorily on their respective latent variables (eight subjective measures and the outcome of transportation physical activity). For transportation physical activity, (Table 3) almost all of the locations (including fast food restaurant, coffee shop, religious institutions, nearest bus stop, post office, etc.) were significantly loaded on transport physical activity. Medicinal shops were not, partly because the community-based polyclinics are providing almost all necessary health care to the elderly at public subsidized rates. The effect of senior activity center and hub could also be explained by community club and residents' committee.

CFA generated eight subjective measures of built environment, namely residential density, well connected streets in the neighborhood (street connectivity), land use mix access, infrastructure walk cycle, aesthetics, traffic safety, crime safety and land use density, and details shown in Table 4 and 5 below. In each factors, the 
significant manifest variables $(p<0.05)$ were identified and retained for explaining eight subjective measures of built environment The results were compared with the full list of manifest variables with the aid of Akaike and Bayesian Information Criteria. The results of the factor analyses were found to be satisfactory.

\section{Competing interests}

The authors hereby declare that there is no conflict of interests in relation to the study.

\section{Authors' contributions}

Authors NTP, SPC, HLM, MSZN and FKS had full access to the data collected by the study and take responsibility for the integrity of the data and its accurate analysis. Author TPN formulated the hypothesis, designed the study, and reviewed both the data and the manuscript, while HLM, SPC, MSZN and FKS reviewed the literature, conducted the study, performed data analysis, and drafted and reviewed the manuscript. All co-authors participated in the review of the literature, study design and data collection, and had reviewed all the drafts of the manuscript. All authors read and approved the final manuscript.

\section{Acknowledgment}

The authors would like to express their heartfelt thanks to the following voluntary welfare organizations for their support of the Singapore Longitudinal Ageing Studies: Geylang East Home for the Aged, Presbyterian Community Services, Thye Hua Kwan Moral Society (Moral Neighborhood Links), Yuhua Neighborhood Link, Henderson Senior Citizens' Home, NTUC Eldercare Co-op Ltd, Thong Kheng Seniors Activity Centre (Queenstown Centre) and Redhill Moral Seniors Activity Centre.

\section{Funding support}

The study was supported by the Agency for Science Technology and Research (A*STAR) Biomedical Research Council (BMRC) [Grant: 08/1/21/19/ 567] and National University of Singapore Ageing Integrated Research Cluster (AIRC) [Grant: DPRT/AGE/2010/10].

\section{Author details}

'Gerontology Research Programme, Department of Psychological Medicine, Yong Loo Lin School of Medicine, National University of Singapore, Kent Ridge, Singapore. ${ }^{2}$ Centre for Sustainable Asian Cities, National University of Singapore, Singapore, Singapore. ${ }^{3}$ Department of Rehabilitation Care, National University Health System, Kent Ridge, Singapore. ${ }^{4}$ Department of Geriatric Medicine, Alexandra Hospital, south-western, Singapore. ${ }^{5}$ Department of Medicine, Yong Loo School of Medicine, National University of Singapore, Kent Ridge, Singapore. ${ }^{6}$ Department of Medicine, University of Melbourne, Melbourne, Australia. ${ }^{7}$ Cardiovascular Research Institute, National University Heart Center, Kent Ridge, Singapore. ${ }^{8}$ Department of Mathematics \& Statistics, Faculty of Science, Technology \& Engineering, La Trobe University, Melbourne, Australia. ${ }^{9}$ Center for Liveable Cities, Ministry of National Development, Singapore, Singapore. ${ }^{10}$ Yong Loo Lin School of Medicine, Department of Psychological Medicine, National University Hospital, National University of Singapore, 5 Lower Road, Kent Ridge 119074, Singapore.

Received: 15 December 2014 Accepted: 4 September 2015 Published online: 15 September 2015

\section{References}

1. Brownson RC, Hoehner CM, Day K, Forsyth A, Sallis JF. Measuring the built environment for physical activity: State of the science. Am J Prev Med. 2009;36(4S):S99-123.

2. Clarke P, George LK. The role of the built environment in the disablement process. American J Pub Health. 2005;95(11):1933-9.

3. Lin, L, Anne Vernez M. Objective versus subjective measures of the built environment: Which are most effective in capturing associations with walking? Health and Place. 2010;16(2):339-48.

4. Michael Y, Beard T, Choi D, Farquhar S, Carlson N. Measuring the influence of built neighborhood environments on walking in older adults. J Aging Phys Act. 2006;14(3):302-12.
5. McGinn AP, Evenson KR, Herring AH, Huston SL, Rodriguez DA. Exploring associations between physical activity and perceived and objective measures of the built environment. J Urban Health. 2007;84:162-84.

6. Nagel $\mathrm{CL}$, Carlson NE, Bosworth M, Michael YL. The relation between neighborhood built environment and walking activity among older adults. Am J Epidemiol. 2008;168:461-8.

7. Inoue S, Ohya Y, Odagiri Y, Takamiya T, Kamada M, Okada S, et al. James F Sallis, and Teruichi Shimomitsu: Perceived Neighborhood Environment and Walking for Specific Purposes Among Elderly Japanese. J Epidemiol. 2011;21(6):481-90.

8. Singapore Housing and development Board Information website (www.hdb.gov.sg) 2012 report.

9. Sallis JF, Bowles HR, Bauman A, Ainsworth BE, Bull FC, Craig CL, et al. Neighborhood environments and physical activity among adults in 11 countries. Am J Prev Med. 2009;36:484-90.

10. Gay JL, Saunders RP, Dowda M. The relationship of physical activity and the built environment within the context of self-determination theory. Ann Behav Med. 2011;42:188-96.

11. Parra DC. Luis FG, Olga LS, David B, Ross B, Thomas S, Viviola G, Felipe L: Perceived and objective neighborhood environment attributes and health related quality of life among the elderly in Bogota, Colombia. Soc Sci Med. 2010;70:1070-6.

12. Tresidderm M. Using GIS to measure connectivity: an exploration of issues. Portland State University: Field Area Paper; 2005.

13. Frank LD, Salli JF, Conway TL, Chapman JE, Saelens BE, Bachman W. Many pathways from land use to health: associations between neighborhood walkability and active transportation, body mass index, and air quality. Journal of the American Planning Association. 2006;76:75-87.

14. Frank LD, Saelens BE, Powell KE, Chapman JE. Stepping towards causation: Do built environments or neighborhood and travel preferences explain physical activity, driving, and obesity? Soc Sci Med. 2007;65:1898-914.

15. Leslie E, Coffee N, Frank L, Owen N, Bauman A, Hugo G. Walkability of local communities: Using geographic information systems to objectively assess relevant environmental attributes. Health Place. 2007;13:111-22.

16. Oliver L, Schuurman N, Hall A, Hayes M. Assessing the influence of the built environement on physical activity for utility and recreation in suburban metro Vancouver. BMC public Health. 2011;11:959-68.

17. Forsyth A. Twin cities walking study, environment and physical activity: GIS protocols. USA: University of Minnesota and Cornell; 2007.

18. Witten K, Pearce J, Day P. Neighborhood Destination Accessibility Index: a GIS tool for measuring infrastructure support for neighborhood physical activity. Env Plan A. 2011;43:205-23.

19. Tinetti ME. Performance Oriented Assessment of Mobility Problems in Elderly Patients. JAGS. 1986;34:119-26.

20. Corp S. Stata: Release 13 Statistical Software. College Station, TX: StataCorp LP; 2013.

21. Gefen D, Figdon EE, Straub D. An update and extension to SEM guidelines for administrative and social science research. MIS Q. 2011;35:iii-xiv.

22. McDonald RP, Ho MH. Principles and practice in reporting structural equation analyses. Psychol Methods. 2002;7:64-82.

23. Oakes JM, Forsyth A, Schmitz KH. The effects of neighborhood density and street connectivity on walking behavior: The Twin Cities walking study. Epidemiol Perspect Innov. 2007:4:16.

24. Owen N, Cerin E, Leslie E, duToit L, Coffee N, Frank LD, et al. Neighborhood walkability and the walking behavior of Australian adults. Am J Prev Med. 2007;33:387-95. 